\title{
PETUNG DALAM PRIMBON JAWA
}

\author{
Hartono \\ FKIP Universitas Sebelas Maret \\ email: hartono@fkip.uns.ac.id
}

\begin{abstract}
Abstrak
Penelitian ini bertujuan: (a) mengklasifikasikan, (b) mendeskripsikan makna, dan (c) menemukan sistem kognisi dan kearifan lokal petung primbon Jawa. Jenis penelitian ini adalah deskriptif kualitatif.Sumber data penelitian adalah Kitab Primbon Betaljemur Adammakna (KPBA). Tahapan penelitian meliputi: (a) terjemahan harfiah; (b) analisis konteks; (c) analisis ciri-ciri khas primbon; (d) analisis makna primbon; dan (e) menemukan sistem kognisi dan kearifan lokal. Hasil penelitian sebagai berikut. Pertama, petung primbon berdasarkan keperluannya diklasifikasikan menjadi 16 petung, sedangkan berdasarkan simbol yang digunakan diklasifikasikan menjadi 57 petung. Kedua, petung primbon Jawa tidak bisa dipahami hanya berdasarkan makna harfiahnya, tetapi perlu mempertimbangkan makna lain yang membentuknya. Ketiga, petung primbon merupakan akumulasi dari kearifan lokal yang dapat menghasilkan ilmu titen. Ilmu titen dapat membangun sebuah sistem kognisi yang menghasilkan kearifan lokal berisi nasihat bijak untuk generasi mendatang.
\end{abstract}

Kata kunci: petung, primbon Jawa, sistem kognisi, kearifan lokal

\section{PETUNGIN A JAVANESE PRIMBON}

\begin{abstract}
This study aims to: (1) classify, (2) describe meanings, and (3) investigate the cognition system and local wisdom in petung (calculations) in a Javanese primbon (a handbook containing predictions). This was a qualitative descriptive study. The data source was Kitab Primbon Betaljemur Adammakna (KPBA). The research stages included: (a) literal translation; (b) analysis of contexts, (c) analysis of typical characteristics of the primbon, (d) semantic analysis of the primbon, and (e) investigation of the cognition system and local wisdom. The research findings are as follows. First, types of petung in the primbonbased on the needs are classified into 16 types and those based on the symbols are classified into 57 types. Second, petung in a Javanese primbon cannot be conceived based on the literal meaningonly, but other meanings constituting petung should be considered. Third, petung in a primbon is an accumulation of local wisrom resulting in ilmu titen (insight based on repeated observations). Ilmu titen can construct a cognition system resulting in local wisdom containing wise advice for the next generation.
\end{abstract}

Keywords: petung, Javanese primbon, cognition system, local wisdom

\section{PENDAHULUAN}

Salah satu warisan kebudayaan Jawa yang hampir dilupakan orang adalah kitab-kitab primbon. Kitab-kitab primbon tersebut diwariskan turun-temurun yang sampai saat ini masih masih digunakan sebagian masyarakat Jawa digunakan masyarakat Jawa untuk memulai atau melakukan aktivitas sehari-hari. Kitab primbon pada dasarnya merupakan catat- 
an tentang berbagai petung suatu kegiatan atau ritual yang telah dibukukan dengan rapi oleh pujangga, sehingga catatan itu sampai sekarang masih bisa dipelajari dengan mudah.

Kitab primbonJawayang masih digunakan masyarakat diantaranya kitab primbon yang dihimpun oleh Soemodidjojo. Selain itu, pustaka yang membahas tentang primbon Jawa, antara lain Almanak Gampang 1900-2000 oleh S. Resowidjojo (1959) membahas tentang isi Pawukon. Primbon Djawa Pawukon (1966) oleh R. Tanaja. R. Tanaja (1966) dan Sindhunata (2004) membahas tentang isi Pawukon beserta gambarnya. "Sistem Penanggalan Sultan Agung" oleh Marsono (2004) yang membahas pawukon secara umum. Djanuadji (2002) dalam bukunya "Primbon (empat macam petung)", membahas empat macam petung, yaitu mendirikan rumah, pindah rumah, berumah tangga, dan selamatan orang meninggal. Hadisiswaya (2011) dalam bukunya yang berjudul "Petungan Jawa, Memilih Cinta dan Jodoh" membahas masalah mencari kesesuaian watak dan weton 'hari kelahiran', meraih keserasian pasangan dalam susah dan bahagia, petung menentukan hari baik pernikahan, dan petung mendapatkan kebahagiaan rumahtangga. Hadisiswaya (2009) juga menulis "Primbon Usaha" membahas usaha yang tepat dan cocok melalui hitungan hari kelahiran, watak, dan keharmonisan antara diri dengan alam semesta. Buku lain yang membahas primbon adalah Serat Centhini (Sumahatmaka, R.M.A, 1981). Serat Centhini atau juga disebut Suluk Tambanglaras atau Suluk Tambangraras Amongraga, merupakan salah satu karya sastra terbesar dalam kesusastraan Jawa Baru. Serat Centhini menghimpun segala macam ilmu pengetahuan dan kebudayaan Jawa, agar tak punah dan tetap lestari sepanjang waktu. Serat Centhini disampaikan dalam bentuk tembang dan penulisannya dikelompokkan menurut jenis lagunya. Semula ada 12 jilid terdiri atas 280 lagu kemudian dilakukan penggubahan menjadi 725 lagu. Wibawa (2013: 328) menyatakan bahwa nilai filosofi Jawa dalam Serat Centhini tercermin dalam nilai kesempurnaan hidup (ngudi kasampurnan) dan filsafat asal dan arahnya yang ada (sangkan paraning dumadi); dan tercermin dalam landasan ontologis, epstimologis, dan aksiologis).

Salah satu kitab primbon yang terkenal sampai saat ini dan masih digunakan sebagai rujukan untuk menentukan perjodoham, membuat rumah, pindah rumah, kelahiran bayi, bepergian, menentukan waktu yang baik,membeli hewan ternak, bercocok tanam, meminta/menolak hujan, mengetahui sifat keris, mengetahui penyebab sakit manusia, mengetahui watak hari orang meninggal dunia,dan sebagainya adalah "Kitab Primbon Betaljemur Adammakna" (selanjutnya disingkat KPBA). Primbon inilah yang memuat berbagai macam catatan tentang kehidupan manusia mulai dari lahir sampai dengan meninggal dunia. Catatan-catatan tersebut sering disebut petungyang baik dan yang buruk. Ahimsa-Putra (2012: 383) menyatakan bahwa nilai-nilai suatu kebudayaan tidak hanya mengenai hal-hal yang baik atau bernilai saja, tetapi juga mengenai hal-hal yang buruk atau tidak bernilai, karena yang baik tidak akan dapat diketahui tanpa adanya yang buruk.

Di saat masyarakat mengalami konflik yang mempengaruhi segi-segi kehidupan sehari-hari, masyarakat Jawa masih mempercayai petung, tetapi seiring perkembangan zaman timbul berbagai pemaknaan terhadap petung Kitab Primbon Jawa. Oleh karena itu, perlu diketahui apa dan bagaimana sebenarnya petung. Penelitian ini memfokuskan pada tiga permasalahan, yaitu: (1) klasifikasi petung dalam primbon Jawa, (2) ditinjau dari segi semantik makna makna apa saja yang terkandung dalam petung primbon Jawa, dan (3)sistem kognisi dan kearifan lokal yang ditemukan dalam petung primbon Jawa. 


\section{METODE}

Metode penelitian ini menggunakan tiga tahapan strategi, yaitu: (1) penyediaan data, (2) analisis data, dan (3) penyajian analisis data (Sudaryanto, 1993: 57).Data penelitian disediakan dengan langkahlangkah: (1) penentuan data dan sumber data, dan (2) teknik penyediaan data. Sumber data dalam penelitian ini berupa primbon Jawa KPBA, sedangkan datanya adalah berbagai petung dalam ritual Jawa. Metode yang digunakan adalah metode deskriptif kualitatif. Metode ini dapat mengungkapkan berbagai informasi kualitatif yang disertai dengan deskriptif yang diteliti, akurat, serta penuh rasa dan nuansa (Sutopo, 1996: 136). Metode penelitian ini menggunakan strategi berpikir fenomenologis yang bersifat lentur dan terbuka serta dipusatkan analisisnya secara induksi dengan meletakan data penelitian bukan saja sebagai alat pembuktian, tetapi juga sebagai modal dasar untuk memahami fakta yang ada (Sutopo, 1996). Langkah-langkah analisis data: (1) terjemahan harfiah dan bebas; (2) analisis konteks (sesuai dengan faktor yang diteliti); (3) analisis klasifikasi beserta ciri-ciri khas primbon; (4) analisis makna primbon; dan (5) menemukan sistem kognisi dan kearifan lokal.

\section{HASIL PENELITIAN DAN PEMBA- HASAN}

Klasifikasi Petung Primbon Jawa

Petungdalam primbom Jawa disampaikan dengan menggunakan ungkapan metaforis. Supriyadi (2013: 312) menyatakan bahwa ungkapan metaforis dimaksudkan untuk memperoleh efek etis dan estetis. Efek etis dan estetis disampaikan disampaikan dengan menggunakan simbol-simbol yang melambangkan sesuatu yang kongkret untuk tujuan yang abstrak atau sebaliknya, yaitu untuk tujuan yang abstrak dengan menggunakan simbolsimbol yang kongkret.
Petung dalam primbon Jawa dapat diklasifikasi berdasarkan keperluannya, simbol yang digunakan, dan kategori simbol yang digunakan. Berdasarkan keperluannya, petung dalam primbon Jawa dapat diklasifikasikan menjadi 16 petung, yaitu: (1) petung salaki rabi 'perjodohan', (2) petung gawe omah 'membuat rumah', (3) petung bayi lair 'kelahiran bayi', (4) petung lelungan 'bepergian', (5) petung sa'at agung 'saat agung', (6) petungboyongan 'pindah rumah', (7) petung pamilihing desa kanggo gawe omah 'pemilihan desa untuk membuat rumah', (8) petungsa'at dina lan pasaran'saat hari dan pasaran', (9) petungwataking wesi aji 'sifat besi bertuah' atau 'keris', (10) petungimpen 'mimpi', (11) petung kalamudheng 'kalamudheng', (12) petung kelangan 'kehilangan', (12) petung tuku kewan 'membeli hewan ternak', (14) petungnenandur 'bercocok tanam', (15) petung udan 'hujan', dan (16) petung lelarane manungsa 'penyebab sakit manusia'.

Berdasarkan simbol yang digunakan, petungdalam primbon Jawa dapat diklasifikasikan menjadi 57 petung yang berisi simbol-simbol, seperti terdapat dalam Tabel 1.

Data (1) petung salaki rabi 'petungperjodohan' dengan simbol-simbol: gentho, gembili, Sri, punggel (KPBA, 16). Misalnya:

Wetone penganten lanang wadon, neptune dina lan pasaran digunggung, banjur kabage 4, turah pira.Yen turah 1 gentho. Yen turah 2 gembili. Yen turah 3 sri. Yen turah 4 punggel.

'Hari kelahiran suami dan istri neptu hari dan (pasaran) keduanya dijumlahkan dan hasilnya dibagi 4 akan sisa berapa. Jika sisa 1 gentho. Jika sisa 2 gembili. Jika sisa 3 sri. Jika sisa 4 punggel'.

Dalam petung tersebut terdapat simbol-simbol: gentho, gembili, Sri, punggel. Soemodidjojo (2005 dalam KPBA, 16) dijelaskan bahwa gentho dianalogikan 
Tabel 1. Klasifikasi Simbol Petung

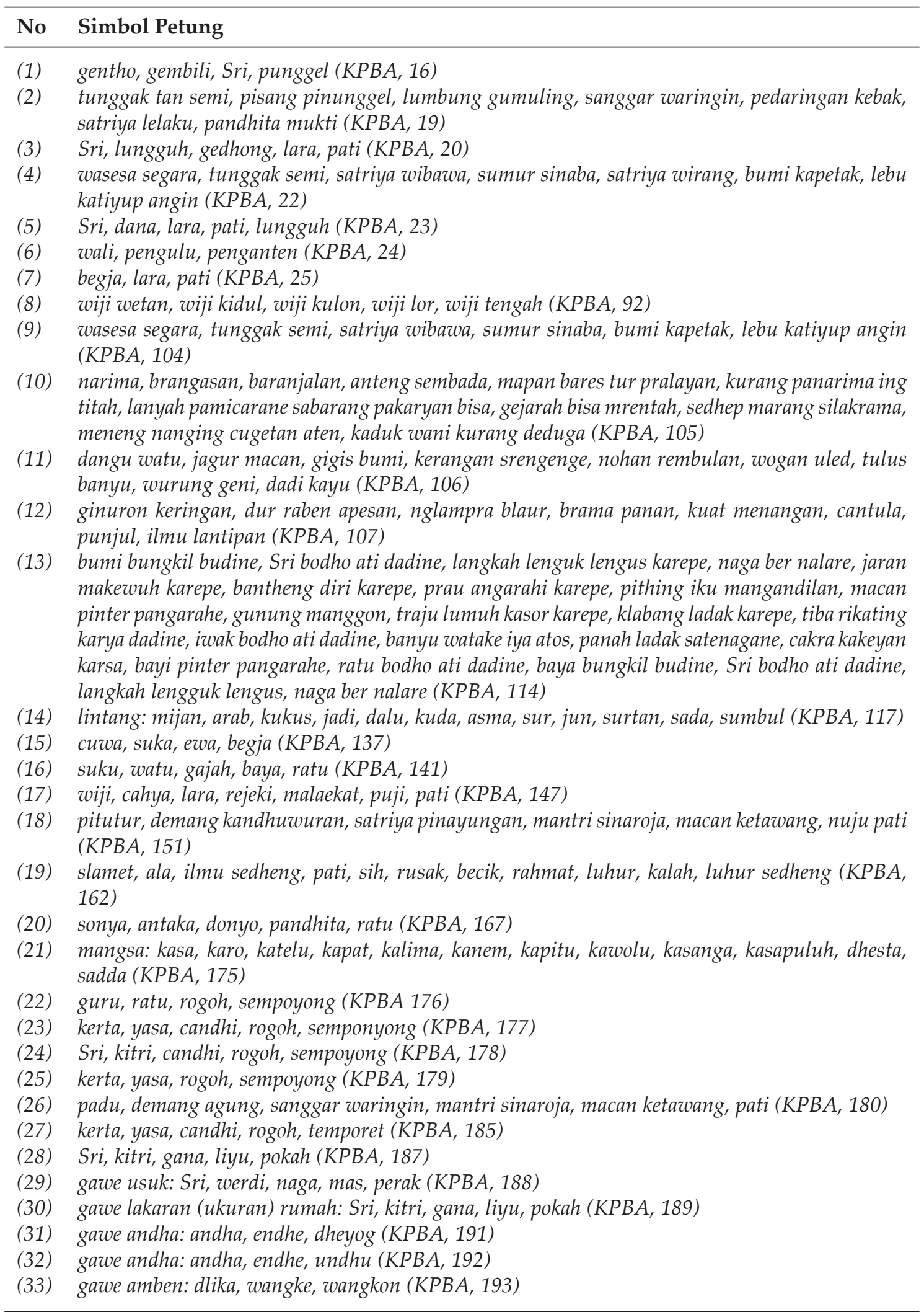


(34) gawe sumur: 1 dhepa Sri, 2 dhepa donya, 3 dhepa arta, 4 dhepa suwarga, 5 dhepa naraka (KPBA, 197)

(35) gawe sumur: tlaga, kali, segara, sendhang (KPBA, 199)

(36) pralambang: janggleng, celeng, nyangking, kithing (KPBA, 206)

(37) siti, sengkali, arjuna mangan ati, randha tunggu donya, dhandhang tunggu nyawa (KPBA, 218)

(38) dina, sasi, tahun, windu (KPBA, 223)

(39) rajeg wesi, seman, kala luweng, tulus (KPBA, 273)

(40) sanget, salu, saru, sanja (KPBA, 276)

(41) adam, kawa, iblis (KPBA, 277)

(42) pisang, waragang, sanggar, banyu, bale, waringin (KPBA, 278)

(43) kena sengkala, enggal mulih, ora mulih (KPBA, 285)

(44) parane: mangetan, mangulon, mangalor, mangidul $(K P B A, 286)$

(45) barang: ora ketemu, ketemu, lepas parane (KPBA, 287)

(46) ora ketemu, isa ketemu, ora ketemu nuli lara (KPBA, 288)

(47) kancane, wong tunggal omah, wong adoh (KPBA, 289)

(48) lanang, wadon, samar (KPBA, 290)

(49) ireng, mbambang awak, semu putih (KPBA, 291)

(50) uwit, epang, godhong, kleyang (KPBA, 292)

(51) Muhammad, Abu Bakar, Ngumar, Ngusman, Ngali (KPBA, 296)

(52) angin, lintang, banyu, srengenge, geni, sasi, bumi (KPBA, 297)

(53) Akhmad, Ngijrail, Yusuf, Brahim, Jabarail (KPBA, 298)

(54) suku, watu, gajah, buta, ratu (KPBA, 302)

(55) oyot, uwit, godhong, uwoh (KPBA, 303)

(56) Dite kenaba, Soma warjita, Anggara rekata, Buda mahesaba, Respati mintuna, Sukra mangkara, Tumpak menda (KPBA, 306)

(57) sabda, guna, tirta, wana, lepas (KPBA, 318)

penjahat atau perampok (hal yang tidak baik). Gembili: dianalogikan sejenis tanaman palawija yang banyak buahnya. Sri: merupakan nama dewi kemakmuran. Punggel: merupakan gambaran sesuatu yang terpotong/terputus. Secara semantis ungkapan gentho, maknanya jarang memiliki anak (hal yang tidak baik); gembili, maknanya banyak anak; Sri, maknanya banyak rezeki; dan punggel, maknanya salah satu meninggal.

Hadisiswaya (2011: 19) memberikan contoh misalnya hari kelahiran suami Jumat Pon, neptu hari dan pasaran 6 dan 7. Hari kelahiran istri Rabu Pahing, neptu hari dan pasaran adalah 7 dan 9. Keduanya dijumlahkan, hasilnya adalah 29 . Selanjutnya 29 dibagi 4 mempunyai sisa 1 , bilangan 1 jatuh pada gentho, maknanya jarang memiliki anak, hal tersebut kurang baik. Ungkapan gentho melambangkan seorang penjahat atau perampok, mewakili makna tidak baik. Pasangan pengantin jika jatuh pada ungkapan gentho maknanya tidak memiliki anak. Tidak memiliki anak adalah tidak baik merujuk pada perilaku yang tidak baik. Ungkapan gembili melambangkan tanaman sejenis palawija yang memiliki buah kecil-kecil dalam jumlah yang banyak. Pasangan pengantin jika jatuh pada ungkapan gembili maknanya banyak anak. Banyak anak merujuk pada referens tumbuhan yang banyak buahnya. Ungkapan Sri melambangkan dewi kemakmuran, dewi yang menguasai sandhang pangan, dewinya padi. Pasangan pengantin jika jatuh pada Sri maknanya banyak rezeki. Banyak rezeki merujuk pada referens kemakmuran.Ungkapan punggel melambangkan tanaman yang bagian ujungnya putus. Pasangan pengantin jika jatuh pada punggel maknanya salah satu meninggal. Salah satu meninggal merujuk pada referens putusnya bagian ujung dari tumbuhan. 


\section{Makna yang Terkandung dalam Petung Primbon Jawa}

Bahasa figuratif ialah bahasa yang digunakan untuk mengatakan sesuatu dengan secara tidak langsung mengungkapkan makna. Dengan demikian kata atau bahasanya bermakna kias atau makna lambang. Pendapat Djajasudarma (1997:18) dalam buku Semantik bahwa stilistika adalah makna yang berhubungan dengan situasi sosial penutur. Di dalam bahasa Inggris, stilistik adalah cabang linguistik yang mempelajari ciri-ciri pembeda secara situasional sebagai varietas bahasa dan stilistika mencoba menyusun prinsip-prinsip yang dipertimbangkan untuk pilihan tertentu, disusun oleh individu atau kelompok sosial dalam menggunakan bahasanya. Dengan demikian masalah stilistika jelas berbeda dengan gaya bahasa, namun berhubungan dengan gaya bahasa karena gaya bahasa sebenarnya adalah sebuah majas (figure of speech).

Semantik sebagai studi tentang makna merupakan masalah pokok dalam komunikasi. Kebutuhan untuk memahami semantik menjadi semakin mendesak karena komunikasi menjadi faktor yang semakin penting di dalam organisasi sosial, Semantik juga merupakan pusat studi tentang pikiran manusia, yaitu proses berpikir, kognisi, dan konseptual. Semua ini saling kait-mengait dengan cara kita mengklasifikasikan dan mengemukakan pengalaman kita tentang dunia nyata ini melalui bahasa (Leech, 2003: 1).Semantik di dalam bahasa Indonesia berasal dari bahasa Inggris semantics, dari bahasa Yunani sema (nomina) 'tanda': atau dari verba samaino 'menandai', berarti'. Istilah tersebut digunakan pakar bahasa untuk menyebutkan bagian ilmu bahasa yang mempelajari makna (Djajasudarma, 1999: 1). Pengertian makna (sense-bahasa Inggris) dibedakan dari arti (meaning-bahasa Inggris) di dalam semantik. Makna adalah pertautan yang ada di antara unsur-unsur bahasa itu sendiri (Djajasudarma,1999:5). Makna atau arti hadir dalam tatabahasa (morfologi dan sintaksis) maupun leksikon. Jadi semantik dapat dibagi menjadi semantik gramatikal dan semantik leksikal (Verhaar, 1996: 385). Semantik leksikal menyangkut makna leksikal. Semantik leksikal secara leksikologis mencakup segi-segi yang agak banyak jumlahnya. Antara lain, ada pokok-pokok berikut: (a) makna dan referensi, (b) denotasi dan konotasi, (c) analisis ekstensional dan analisis intensional, (d) analisis komponensial, (e) makna dan pemakaiannya, (f) kesinoniman, keantoniman, kehomoniman, dan kehiponiman (Verhaar,1996: 388-389). Makna leksikal dalam penelitian ini berdasarkan pada kamus Baoesastra Djawa oleh W. J. S. Poerwadarminta (1939), kamus Bausastra Jawa Indonesia oleh S. Prawiraatmojo (1981), dan kamus Jawa Kuna-Indonesia (1995) oleh P. J. Zoetmulder yang diterjemahkan oleh Darusuprapta dan Sumarti Suprayitna.

Analasis semantik dalam penelitian ini lebih cenderung ke makna gramatikal, karena tidak setiap komponen petung cocok untuk dimaknai secara leksikal. Hal tersebut disebabkan data petung sebagian besar berupa kata atau kelompok kata yang bermakna kias, seperti contoh berikut.

Dalam kegiatan-kegiatan penting, sebagian besar orang Jawa masih menggunakan petung dengan mengacu pada KPBA.Petung dalam menentukan pasangan pengantin ada petungsalaki rabi 'perjodohan' yang merupakan hasil petung neptudina lan pasaran nalika lair 'petungneptu hari dan pasaran ketika lahir' dari pengantin laki-laki dan perempuan yang dijumlahkan kemudian dibagi 10 atau 7, hasilnya masih sisa berapa. (Neptu yang biasa digunakan adalah hari: Minggu $=5$, Senin $=4$, Selasa $=3$, Rabu $=7$, Kamis $=8$, Jumat $=6$, dan Sabtu $=9$; dan neptu pasaran: Legi $=5$, Paing $=9$, Pon $=$ 7 , Wage $=4$, Kliwon $=8$ (Soemodidjojo, 
2005: 7). Bila hasilnya sisa 1: wasesa segara 'kekuasaan samudra', sisa 2: tunggak semi 'tonggak pohon yang tumbuh', sisa 3: satriya wibawa 'orang yang berwibawa', sisa 4 sumur sinaba 'sumber air', sisa 5: satriya wirang 'ksatria yang malu, sisa 6: bumi kapetak 'tanah kuburan', sisa 7: lebu katiyup angin 'debu tertiup angin'. Masingmasing ungkapan tersebut memiliki watak 'sifat' yang berbeda: wasesa segara memiliki sifat: kamot 'dapat menerima segala sesuatu baik atau buruk', jembar budine 'luas pengetahuan/budi pekertinya', sugih pangapura 'pemaaf', gedheprabawane 'besar pengaruhnya' (Soemodidjojo, 2005: 17). Sifat-sifat itu dipercaya sebagai gambaran watak 'sifat' pasangan pengantin di kemudian hari. Demikian juga bila sisa 2 s.d. 7 memiliki watak 'sifat' yang mengandung kearifan lokal yang merupakan hasil pemikiran kolektif sebagian besar masyarakat Jawa.

Berdasarkan hasil wawancara dengan informan, petung dalam bepergian mencari nafkah atau keperluan lain ada petung kliyeg-mentheg-jotho-kemil. Kliyeg 'capai' (netpu 9, 13, 17; mentheg 'berat'; (neptu 10, 14, 18); jotho 'kecewa' (neptu 7, 11, 15); kemil 'selalu makan' (neptu 8, 12, 16). Artinya orang yang bepergian tidak mendapatkan apa-apa kecuali capai saja disebut dengan ungkapan kliyeg; orang yang bepergian akan mendapatkan hasil yang sesuai dengan harapan disebut dengan ungkapan mentheg 'berat'; orang yang selalu gagal mendapatkan sesuatu diungkapkan dengan jotho dari kata menjotho 'kecewa'; orang yang bepergian selalu mendapat suguhan makanan disebut dengan ungkapan kemil/ngemil 'selalu makan'.

Berdasarkan hasil wawancara dengan informan, petung orang yang meninggal dunia dilihat dari neptu dina 'kekuatan hari' dan pasaran dalam petunggunungjurgug-segara-asad. Bila petung jatuh pada gunung 'gunung' perlambang keluarga yang ditinggal akan kuat dan sentosa seperti gunung; jugrug 'runtuh' perlambang keluarga yang ditinggal akan mengalami kehancuran, segara 'samudra' perlambang keluarga yang ditinggal akan hidup damai sejahtera, banyak rezeki, dan luas jangkauannya seperti luasnya segara 'samudra; asad 'kering' perlambang keluarga yang ditinggal akan kekurangan harta benda atau miskin. Itulah beberapa contoh catatan petung yang ditulis dalam KPBA yang masih diuri-uri 'dilestarikan' sampai sekarang. Oleh karena itu, keberadaan KPBA ini cukup penting dalam rangka menjaga adat, tradisi, dan budaya. Selain catatan diatas masih banyak lagi catatan-catatan lainnya yang perlu diketahui khususnya orang Jawa yang masih memegang teguh adat, tradisi, dan budaya ini.

Misalnya dalam petung Miwiti Gawe Omah 'Memulai Membuat Rumah' terdapat petung: guru, ratu, rogoh, sempoyong (KPBA 176). Simbol guru melambangkan tuntunan. Memulai membuat rumah jika jatuh pada petung tersebut maknanya kelak sebagai tumpuan bertanya, selalu mendatangkan rezeki, jauh dari halangan, dan selalu beruntung. Makna tersebut merujuk pada referens tuntunan. Simbol ratu melambangkan pengayoman. Memulai membuat rumah jika jatuh pada petung tersebut maknanya disegani oleh sesamanya, jauh dari malapetaka, dan selalu datang rezekinya. Makna tersebut merujuk pada referens pengayoman. Simbol rogoh melambangkan kehilangan. Memulai membuat rumah jika jatuh pada petung tersebut maknanya sering mengalami kecurian. Makna tersebut merujuk pada referens kehilangan. Simbol sempoyong melambangkan goyah. Memulai membuat rumah jika jatuh pada petung tersebut maknanya sering mengalami sakit dan kesusahan. Makna tersebut merujuk pada referens goyah.

Contoh lain misalnya dalam petung nenandur 'Bercocok Tanam' ada petungoyot, uwit, godhong, uwoh (KPBA, 303). Simbol oyot melambangkan akar di dalam tanah. Bercocok tanam jika jatuh pada pe- 
tung tersebut maknanya akan menghasilkan akar, jadi jika yang ditanam adalah tanaman yang hasilnya bukan pada akar, misalnya buah-buahan, kayu-kayuan, dan daun-daunan, hasilnya tidak akan baik/memuaskan. Dalam petung tersebut sebaiknya yang ditanam yang menghasilkan akar.

Petung dalam membuat tangga ada petung andha, endhe, dheyog'. Ungkapanandha melambangkan tingkatan/meningkat. Membuat tangga jika jatuh pada ungkapan tersebut maknanya baik. Makna tersebut merujuk pada referens meningkat. Ungkapan endhe melambangkan terlepas. Terlepas dari yang punya. Membuat tangga jika jatuh pada ungkapan tersebut maknanya cepat rusak dan sering dipinjam. Makna tersebut merujuk pada referens terlepas. Ungkapan dheyog melambangkan cacat. Membuat tangga jika jatuh pada ungkapan tersebut maknanya tangga yang jahat, karena sering menjatuhkan orang jika dipergunakan. Makna tersebut merujuk pada referens cacat (Soemodidjojo, 2005: 139).

Petung dalam memilih pusaka keris ada petungsiti, sengkali, arjuna mangan ati, randha tunggu donya, dhandhang tunggu nyawa dengan cara menghitung panjang dan lebamya keris dengan ibu jari tangan. Ungkapan siti melambangkan tempat. Memilih keris jika jatuh pada Ungkapan tersebut maknanya berwatak sebagai pelindung, banyak memberi maaf, menunjukkan kebaikannya. Makna tersebut merujuk pada referens tempat. Ungkapan sengkali melambangkan dermawan. Memilih keris jika jatuh pada Ungkapan tersebut maknanya wataknya suka memberi, murah tangan, jika marah berbahaya. Makna tersebut merujuk pada referens dermawan. Ungkapan arjuna mangan ati melambangkan keteguhan. Memilih keris jika jatuh pada ungkapan tersebut maknanya berwatak keras hatinya dan pemarah. Makna tersebut merujuk pada referens keteguhan. Ungkapan randha tunggu donya melam- bangkan kekurangan ditutup dengan kelebihan yang lain. Memilih keris jika jatuh pada ungkapan tersebut maknanya berwatak cukup rezekinya. Makna tersebut merujuk pada referens kekurangan dan kelebihan. Ungkapan dhandhang tunggu nyawa melambangkan kegelapan. Memilih keris jika jatuh pada ungkapan tersebut maknanya berwatak yang memilikinya akan menderita sengsara. Makna tersebut merujuk pada referens kegelapan (Soemodidjojo, 2005: 155).

Berdasarkan pembahasan tersebut, dapat diketahui bahwa makna yang terkandung dalam petung primbon Jawa adalah sebagian besar berupa makna makna kias. Hal itu mengisyaratkan bahwa dalam memaknai suatu bahasa, termasuk petung primbon Jawa, perlu memperhatikan arti kata yang terdapat dalam komponen makna. Suatu kata mengandung arti, arti mengandung makna. Dengan demikian, dalam memahami makna petung primbon Jawa tidak bisa dipahami hanya berdasarkan makna harfiahnya atau makna leksikalnya, tetapi perlu mempertimbangkan makna lain yang terkandung dalam arti sebuah kata atau simbol yang membentuk petung primbon Jawa.

\section{Sistem Kognisi dan Kearifan Lokal da- lam Petung Primbon Jawa}

Keesing (1981: 46) mengatakan bahwa kebudayaan adalah: sistem adaptasi; sistem kognisi; sistem struktural; sistem simbolis; sistem ideasional. Dalam uraian tersebut, ahli itu mengatakan bahwa kebudayaan merupakan sistem kognisi. "Cognitive system is a system of knowledge, beliefs, and values. Culture is an idealized cognitive system that exits in the minds of individiual members of society" yang artinya sistem kognisi adalah suatu sistem pengetahuan, kepercayaan, dan nilai-nilai. Budaya adalah sistem kognisi yang diidealkan yang ada dalam pikiran masingmasing anggota masyarakat. 
Agar dapat memahami itu semua diperlukan cabang ilmu yang mengkaji tentang hal itu, yaitu antropologi kognitif. Asher (1994: 588) mengatakan tentang bidang ilmu tersebut seperti berikut. "Focusing on the dynamic interrelations between knowledge and activity, mind and action, cognitive anthropologists investigate this and related questions". Memusatkan pada antarhubungan yang dinamis antara aktivitas dan pengetahuan, tindakan dan pikiran, ahli-ahli antropologi kognitif menyelidiki hal-hal ini dan pertanyaan-pertanyaan yang berhubungan. Lebih lanjut dikatakan Asher (1994: 589) bahwa:"The dicipline of cognitive anthropology which synthesizes perpectives from anthropology, linguistics, and cognitive science is founded on the enduring assumption that cultural knowledge is constructed in activity and is encoded directly and indirectly in words; grammatical patterns, utterences and discourse" yang artinya disiplin antropologi kognitif yang mensintesiskan berbagai perspektif dari antropologi, linguistik, dan sains kognitif didirikan dengan asumsi yang tetap bahwa pengetahuan budaya disusun dalam aktivitas dan dikodekan secara langsung maupun tak langsung dalam kata-kata, pola-pola gramatikal, tuturan, dan wacana.

Istilah "kearifan lokal" terjemahan dari "local genius" dengan arti kemampuan kebudayaan setempat dalam menghadapi pengaruh kebudayaan asing pada waktu kedua kebudayaan tersebut berhubungan. Pendapat lain, Ahimsa-Putra (1996: 5) mendefinisikan kearifan lokal sebagai berikut: perangkat pengetahuan dan praktik-praktik pada suatu komunitas, baik yang berasal dari generasi-generasi sebelumnya maupun dari pengalamannya berhubungan dengan lingkungan dan masyarakat lainnya untuk menyelesaikan secara baik dan benar persoalan dan atau kesulitan yang dihadapi, yang memiliki kekuatan seperti hukum maupun tidak.
Menurut Supriadi (2012: 1) nilai-nilai kearifan lokal sebagai pancaran kultural bangsa Indonesia telah lama dikenal dalam kekayaan budaya dan peradapan yang bermartabat. Orang Jawa zaman dahulu ketika memilih calon menantu umumnya menggunakan kriteria bibit, bobot, bebet. Dalam Baoesastra Djawa, Purwadarminta (1939) disebutkan bahwa bobot $=$ kekayaan, bebet $=$ kain/pakaian yang berarti kehormatan. Bibit artinya benih, maksudnya asal-usul, keturunan atau silsilah, dan garis mana seseorang dilahirkan. Bobot artinya takaran berat, maksudnya adalah kecakapan, kemampuan, kepandaian atau pendidikan. Bebet artinya harta atau kehormatan. Tiga kriteria tersebut, orangtua pada umumnya menghendaki agar menantunya adalah seorang yang memenuhi syarat, yakni: keturunan orang baik-baik, keluarga terpandang (bibit), berkemampuan tinggi, pandai, terpelajar/pendidikan tinggi (bobot), dan dari keluarga terhormat (bebet). Dengan berpedoman pada tiga kriteria itu orang tua berkeyakinan anaknya bakal bahagia, sehingga martabat orang tua turut terangkat. Karena pertimbangan psikologis seperti itulah acuan cara memilih calon pasangan hidup ini sekarang masih banyak dianut orang, meski secara formal dan terbuka orang tidak lagi memakainya (Tartono, 2009: 94).

Sistem kognisi yang ditemukan dalam petung salaki rabi 'perjodohan' adalah: siji pesthi, loro jodho, telu tibaning wahyu, papat drajat, lima bandha. Pesthi artinya pasti, maksdunya kematian; jodho berarti jodoh atau pasangan hidup; tibaning wahyu artinya keberutungan; drajat berarti kedudukan; dan bandha artinya harta kekayaan. Kelima hal itu merupakan sistem kognisi yang diyakini oleh orang Jawa sebagai puncak-puncak hidup manusia yang berada di wilayah kekuasaan Tuhan. Terhadap kelimanya orang sebagai titah (ciptaan) tidak mempunyai hak apa-apa selain pasrah atau berserah diri. Terhadap 
kelima hal itu orang hanya boleh dan bisa berupaya, misalnya mengusahakan agar badan sehat sehingga panjang umur, kalau sakit dibawa ke rumah sakit untuk berobat, namun orang tidak mempunyai hak untuk menentukan dan mengetahui kapan dia mati. Orang boleh memohon, namun Tuhanlah yang berhak mengabulkan, menunda, atau menolaknya. Manusia boleh merencanakan, Tuhanlah yang menentukan (Tartono, 2009: 396-397).

Orang tua yang memiliki anak yang sudah dewasa, terutama anak perempuan selalu khawatir kalau anaknya terlambat menikah dan menjadi perawan tua. Oleh karena itu, orang tua selalu berharap anaknya cepak jatukramane. Cepak berarti dekat, jatukrama berarti pasangan hidup dalam berkeluarga, suami atau istri. Cepak jatukramane berarti calon yang akan menjadi pasangan hidup sudah dekat. Tidak lama lagi seseorang akan bisa menyanding calon pasangan hidup, sehingga hidupnya menjadi lengkap. Kearifan ini menurut filosofi Jawa, berarti orang hidup dikatakan lengkap atau sempurna jika telah memiliki, salah satunya, pasangan hidup atau telah menikah. Maka doa dan harapan yang biasa disampaikan ketika usia seseorang sudah dianggap layak untuk menikah adalah: muga-muga cepak jatukramane 'semoga cepat menikah', dan akhirnya jika sudah menikah doanya: muga-muga enggal diparingi momongan'semoga cepat dikaruniai anak' oleh Tuhan (Tartono, 2009: 109).

Berdasarkan filosofi Jawa, seorang dikatakan hidupnya sudah lengkap jika telah memiliki: wisma, wanita, turangga, kukila, pusaka. Wisma artinya rumah (tempat tinggal tetap); wanita artinya perempuan atau pendamping hidup; turangga artinya kuda atau kendaraan; kukila artinya burung atau hiburan; pusaka artinya senjata atau pekerjaan atau kepandaian (Tartono, 2009: 445). Menurut sistem kognisi orang Jawa, seseorang yang sudah dewasa dikatakan terpenuhi martabat- nya manakala telah memiliki kelima hal tersebut, yaitu: sudah menikah (memiliki wanita bagi pria), punya pendamping, memiliki rumah atau tempat tinggal tetap, memiliki kendaraan, memiliki sarana hiburan, dan pendidikan/pekerjaan tetap. Kalau kelima hal tesebut sudah dimiliki, lengkap sudah status sosialnya sebagai orang dewasa.

Sebelum menikah, seorang pemuda atau utusan dari orang tua yang mau melamar gadis sebagai istri, kepada orang tua gadis dia mengatakan: ngebun-ebun enjing njejawah sonten. Embun yang jatuh pada pagi hari dinamakan awan-uwun. Hujan (jawah) yang turun pada sore hari juga disebut rarabi atau rabi 'menikah'. Ngebunebun enjing njejawah sonten mengandung arti nyuwun rabi 'minta kawin'. Ungkapan ini juga digunakan orang yang diutus untuk menyampaikan lamaran dari suatu keluarga yang salah seorang anaknya (pemuda) yang ingin memperistri seorang gadis dari keluarga lain. Untuk menyatakan kesungguhan hati si pemuda, serta agar lamarannya dikabulkan, utusan tersebut mengawali kata-kata lamarannya dengan ungkapan ngebun-ebun enjing njejawah sonten. Melalui kalimat itu, utusan bermaksud menyatakan bahwa pemuda dengan segenap jiwa ingin menikahi gadis yang dilamar. Betapa si pemuda sungguh nyuwun rabi, alias minta segera dikawinkan (Tartono, 2009: 317-318).

Sistem kognisi tersebut diwujudkan dalam kearifan lokal bahwa segala sesuatu, termasuk perjodohan sudah ditentukan Tuhan yang Maha Kuasa, namun demikian manusia disarankan untuk berusaha. Berdasarkan hasil analisis ditemukan adanya perjodohan yang baik dan tidak baik. Perjodohan yang baik, yaitu jika jatuh pada petung: Sri, gembili, sanggar waringin, pedaringan kebak, pandhita mukti, lungguh, gedhong, wasesa segara, tunggak semi, satriya wibawa, sumur sinaba, dana, lungguh, penganten, dan begja; sedangkan perjodohan yang tidak baik jika 
jatuh petung: gentho, punggel, tunggak tan semi, pisang pinunggel, lumbung gumuling, satriya lelaku, lara, pati, satriya wirang, bumi kapetak, lebu katiyup angin, lara, pati, dan wali (Soemodidjojo, 2005: 13-18).

Jika perjodohan jatuh pada petung yang tidak baik, maka perlu diupayakan syarat atau tebusan yang sering disebut diwiradati 'dicarikan jalan lain' atau tolak balak. Penolaknya diantaranya: tidak besanan, yaitu salah satu pihak tidak mengadakan resepsi pernikahan; calon pengantin dibuang di tempat sampah kemudian ditemu oleh calon mertua; mencari jalan lain, yaitu ketika pengantin berangkat ke rumah mertua tidak melalui jalan yang lazim dilalui; calon pengantin menghamburhamburkan tanah ke udara; mengadakan selamatan; dan sebagainya (Soemodidjojo, 2005: 17).

Berdasarkan pembahasan tersebut dapat diketahui bahwa sistem kognisi dan kearifan lokal dalam petung primbon Jawa merupakan akumulasi dari kearifan lokal yang pada akhirnya bisa menghasilkan ilmu titen. Ilmu titen ini nantinya akan membangun sebuah sistem kognisi yang menghasilkan beberapa kearifan lokal yang sarat dengan nasihat bijak untuk generasi mendatang. Kearifan-kearifan tersebut diantaranya:

1) Petung salaki rabi 'perjodohan': bibit, bobot, bebet; siji pesthi, loro jodho, telu tibaning wahyu, papat drajat, lima bandha; cepak jatukramane; wisma, wanita, turangga, kukila, pusaka.

2) Petung gawe omah 'membuat rumah': alon-alon waton kelakon, kebat kliwat; mumpung sugih bajur sumugih; narima ing pandum; orangaya; sing ubet ngliwet; kabeh gaweyan becik sing peting halal.

3) Petung bayi lair 'kelahiran bayi': tunggak semi; tunggak jarak marjak, tunggak jati mati; kladuk wani kurang deduga; ilmu lantipan; tanggap ing sasmita amrih lantip; anak nggawa rejeki dhewe-dhewe; urip sadrema nglakoni, Gusti sing maringi.
4) Petung lelungan 'bepergian': wong pinter kalah karo wong bejo.

5) Petung sa'at agung 'saat agung': angon wayah.

6) Petungboyongan 'pindah rumah': omahku suwargaku.

7) Petung kalamudheng 'kalamudheng': mangerteni elmu maling ora kanggo maling, nangging kanggo mangerteni pengapesaning maling.

8) Petungnenandur 'bercocok tanam': sapa nandur bakal ngunduh.

9) Petung lelarane manungsa 'penyebab sakit manusia': sabda pandhita ratu tan kena wola-wali.

10)

\section{SIMPULAN}

Setelah dilakukan penelitian, deskripsi, dan analisis data, maka dapat ditarik kesimpulan sebagai berikut. Berdasarkan keperluannya, petung dapat diklasifikasikan menjadi 16 petung, selanjutnya dari 16 jenis petung tersebut, berdasarkan simbol yang digunakan, dapat diklasifikasikan menjadi 57 macam petung. Berdasarkan kategori simbol yang digunakan, petung primbon Jawa dapat diklasifikasikan menjadi simbol: alam, alat rumah tangga, anggota badan, arah mata angin, buah, dewa/dewi, hewan/binatang, hubungan kekerabatan, jabatan, nabi/sahabat nabi, malaikat, makhluk halus, tanaman/bagian dari tanaman, waktu, warna, perhiasan, tokoh wayang, tempat/bangunan, senjata, dan keterangan/keadaan/sifat.

Berdasarkan analisis makna, petung primbon Jawa dapat disimpulkan bahwa makna yang terkandung dalam primbon Jawa adalah sebagian besar berupa makna konotatif atau makna kias. Hal itu mengisyaratkan bahwa dalam memaknai suatu bahasa, termasuk primbon Jawa, perlu memperhatikan arti kata yang terdapat dalam komponen makna. Suatu kata mengandung arti, arti mengandung makna. Dengan demikian, dalam memahami makna primbon Jawa tidak bisa dipahami 
hanya berdasarkan makna harfiahnya atau makna leksikalnya, tetapi perlu mempertimbangkan makna lain yang terkandung dalam arti sebuah kata atau simbol dalam primbon Jawa. Bahasa yang digunakan primbon adalah bahasa yang cenderung arkais (kawi). Bahasa itu tersusun dalam kalimat yang indah, berirama supaya mudah diingat. Kalimat indah itu berisikan leksikon arkais. Pada umumnya anak muda sekarang tidak tahu artinya. Leksikon arkais tersebut dengan sendirinya dibantu oleh afiks arkais. Dalam primbon Jawa, yang penting dicatat adalah perhitungan tentang watak harihari. Setiap hari, baik hari dengan sistem 7 hari (saptawara) ataupun dengan sistem 5 hari pasaran (pancawara) memiliki wataknya sendiri-sendiri. Di samping hari, yang mempunyai watak adalah keris atau wesi aji, membuat alat rumah tangga, orang meninggal, bercocok tanam, dan lain-lain.

Sistem kognisi dan kearifan lokal dalam petung primbon Jawa merupakan akumulasi dari kearifan lokal yang pada akhirnya bisa menghasilkan ilmu titen. Ilmu titen ini nantinya akan membangun sebuah sistem kognisi yang menghasilkan beberapa kearifan lokal yang sarat dengan nasihat bijak untuk generasi mendatang. Orang Jawa percaya bahwa ada kekuasaan Yang Maha Kuasa di luar kekuasaan dirinya. Kekuasaan ini menguasai nasib hidup orang. Nasib ini ditentukan oleh hari lahir, hari melangsungkan pernikahan, hari pada waktu akan mendirikan rumah, atau hari-hari pada waktu mengawali suatu kegiatan sehari-hari. Nasib baik atau buruk sebetulnya dapat dicatat dalam primbon. Orang yang dulu mencatat hal itu adalah orang-orang tua yang selalu memperhatikan perhitungan saat-saat kejadian dan akibatnya. Hal itu sering dinamakan dengan "Ilmu Titen". Ilmu titen ini nantinya akan membangun sebuah sistem kognisi yang menghasilkan beberapa kearifan lokal, salah satunya ber- bentuk petung yang sarat dengan nasihat bijak untuk generasi mendatang.

\section{UCAPAN TERIMA KASIH}

Artikel ini merupakan bagian dari disertasi, khususnya pada pembahasan petung primbon Jawa,yang sedang dilakukan pada Program Pascasarjana Fakultas Ilmu Budaya Universitas Gadjah Mada. Ucapan terima kasih disampaikan kepada Prof. Dr. I Dewa Putu Wijana, S.U., M.A. sebagai promotor, Dr. Inyo Yos Fernandez, dan Prof. Dr. Soepomo Poedjosoedarmo sebagai kopromotor. Ucapan terima kasih juga disampaikan kepada para informan yang membantu penelitian ini. Semoga hasil penelitian ini dapat memberi manfaat dan masukan untuk berbagai kajian bahasa dan sastra yang relevan.

\section{DAFTAR PUSTAKA}

Ahimsa-Putra, H.S. 1996. Etnolinguistik Beberapa Bentuk Kajian. Yogyakarta: Balai Penelitian Bahasa.

Ahimsa-Putra, H.S. 2012. "Baik dan Buruk dalam Budaya Jawa, Sketsa Tafsir Nilai-nilai Budaya Jawa". Patrawidya. Jurnal Terakreditasi N0. 405/AU3/ P2MI-LIPI/2012. Vol. 13, No. 3 Tahun 2012, hlm. 383-410.

Asher, R.E. 1994. The Encyclopedia of Language and Linguistics. Tokyo: Pergamnon Perss.

Djajasudarma, T. Fatimah. 1977. Nilai Budaya dalam Ungkapan dan Peribahasa Sunda. Jakarta: Pusat Pembinaan dan Pengembangan Bahasa.

Djajasudarma, T. Fatimah. 1999. Semantik I Pengantar ke Arah Ihnu Makna. Bandung: PT Refika Aditama.

Djanuadji. 2002. Primbon Empat Macam Petung. Semarang: Effhar Offset.

Hadisiswaya, A.M. 2009. Primbon Usaha. Yogyakarta: Pinus Book Publisher.

Hadisiswaya, A.M. 2011. Petung Asmara Jawa. Yogyakarta: Pinus Book Publisher. 
Keesing, Roger M. 1981. “Theories of Culture" dalam Language, Culture, and Cognition, hal. 42-66. New York: Macmillan Publishing Co., Inc.

Leech, Geoffrey. 2003. Semantik. T (diterjemahkan oleh Partana). Yogyakarta: Pustaka Pelajar.

Marsono. 2004. "Sistem Penanggalan Sultan Agung" dalam Mempertanyakan Jati diri Bangsa. Sumiyati. Suharto. Marsono (Ed.). Yogyakarta: Divisi penerbitan Unit Pengkajian dan Pengembangan Fakultas Ilmu Budaya Universitas Gadjah Mada.

Poerwadarminta. W. J. S. 1939. Baoesastra Djawa. Batavia: J. B. Wolters.

Resowidjojo S. 1959. Almanak Gampang 1900-2000. Jakarta: Dinas Penerbitan Balai Pustaka.

Sindhunata. 2004. Pawukon. Yogyakarta: Bentara Budaya.

Soemodidjojo, R. 1983. Kitab Primbon Bekti Jamal Adammakna. Yogyakarta: Penerbit Soemodidjojo Mahadewa.

Soemodidjojo, R. 2005. Kitab Primbon Betal Jemur Adammakna. Yogyakarta: Penerbit Soemodidjojo Mahadewa.

Soemodidjojo, R. 2008. Kitab Primbon Ajimantrawara, Yoga Brata, Rajah Yoga mantra. Yogyakarta: Penerbit Soemodidjojo Mahadewa.

Soemodidjojo, R. 2008. Kitab Primbon Atassadur Adammakna. Yogyakarta: Penerbit Soemodidjojo Mahadewa.

Soemodidjojo, R. 2008. Kitab Primbon Lukmanakim Adammakna. Yogyakarta: Penerbit Soemodidjojo Mahadewa.

Soemodidjojo, R. t.t. Kitab Primbon Naklatssanjir Adammakna. Yogyakarta: Penerbit Soemodidjojo Mahadewa.

Soemodidjojo, R. t.t. Kitab Primbon Qomarrullsyamsi Adammakna. Yogyakarta: Penerbit Soemodidjojo Mahadewa.

Soemodidjojo, R. t.t. Kitab Primbon Qurasyn Adammakna. Yogyakarta: Penerbit Soemodidjojo Mahadewa.
Soemodidjojo, R. t.t. Kitab Primbon Shahadhatsaahthir Adammakna. Yogyakarta: Penerbit Soemodidjojo Mahadewa.

Sudaryanto, 1993. Metode dan Aneka Teknik Analisis Bahasa. Yogyakarta: Duta Wacana University Press.

Sumahatmaka, R.M.A. 1981. Ringkasan Serat Centini (Suluk Tambanglaras). Cetakan pertama. Jakarta: P.N. Balai Pustaka.

Supriadi,Asep. 2012. “Kearifan Lokal Cerita Sangkuriang: Menuju Ketahanan Bangsa". Meta Sastra. Jurnal Terakreditasi Nomor: 292/Akred-LIPI/ P2MBI/08/2010. ISSN 2085-7268. Volume 5 Nomor 1, Juli 2012, hlm. 1-10

Wibawa, Sutrisna. 2013. "Nilai Filosofi Jawa dalam Serat Centhini". Litera. Jurnal Terakreditasi Nomor: 66b/ DIKTI/Kep/2011. ISSN 1412-2596. Volume 12, Nomor 2, Oktober 2013, hlm. 328-344.

Sutopo H.B. 1996. Metode Penelitian Sosial. Surakarta: UNS press.

Supriyadi. 2013. “Ungkapan-ungkapan Metaforis dalam Puisi-puisi Karya Agus R. Sardjono".Litera. Jurnal Terakreditasi Nomor: 66b/DIKTI/ Kep/2011. ISSN 1412-2596. Volume 12, Nomor 2, Oktober 2013, hlm. 312327.

Tanaja, R. 1966. Primbon Djawa Pawukon. Surakarta: T. B. Peladjar.

Tartono, St.S. 2009. Pitutur Adi Luhur. Ajaran Moral dan Filosofi Hidup Orang Jawa. Yogyakarta: Yayasan Nusatama.

Verhaar J.W.M. 1996. Pengantar Linguistik. Yogyakarta: Gadjah Mada University Press.

Zoetmulder, P.J. 1995. Kamus Jawa Kuna Indonesia (terjemahan Darusuprapta dan Sumarti Suprayitna). Jakarta: P.T. Gramedia Pustaka Utama. 